\title{
Complete Remission of Relapsed Hodgkin's Lymphoma following Brentuximab Vedotin and Gemcitabine Combination Therapy with Severe Hypotension as Possible Treatment- Related Adverse Event: A Case Report
}

\author{
Ibnu Purwanto $^{a} \quad$ Bambang P. Utomo $^{b}$ Ahmad Ghozalib \\ aDepartment of Internal Medicine, Hematology and Medical Oncology Division, Faculty \\ of Medicine, Public Health, and Nursing, Gadjah Mada University, Yogyakarta, Indonesia;

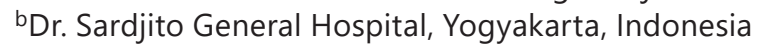

\author{
Keywords \\ Hodgkin's lymphoma · Relapsed $\cdot$ Brentuximab $\cdot$ Complete remission · Adverse event
}

\section{Abstract}

A 40-year-old Asian female with heavily treated relapsed Hodgkin's lymphoma showed complete remission (CR) after receiving 8 cycles of brentuximab vedotin (BV) in combination with gemcitabine as 4 th line treatment. The patient remained in $\mathrm{CR}$ at the 18-month post-treatment follow-up. She developed severe hypotension $(50 / 36 \mathrm{~mm} \mathrm{Hg})$ with upper and lower limb petechiae and edema after the addition of gemcitabine on the 6th cycle of BV. This adverse event resolved after 3 days of treatment with vasopressor and high-dose corticosteroid. The addition of dexamethasone for the subsequent 2 cycles successfully prevented this adverse event from recurring.

(c) 2020 The Author(s).

Published by S. Karger AG, Basel

\section{Introduction}

Hodgkin's lymphoma (HL) is generally associated with a relatively good prognosis, with a 5-year overall survival reported to be around 67-98\% [1]. Nevertheless, some subsets of HL patients still have a poor prognosis, which includes relapsed and treatment-refractory patients [2]. Brentuximab vedotin (BV), an anti-CD30 drug, presents as an effective therapeutic option for these patients. CD30 is expressed in $14-25 \%$ of all B-cell lymphoid malig- 
Purwanto et al.: CR of Relapsed Hodgkin's Lymphoma following BV and Gemcitabine Combination Therapy

nancies and $90 \%$ of all T-cell lymphoid malignancies [3-5]. Overexpression of CD30 contributes toward lymphomagenesis through an anti-apoptotic mechanism, resulting in cell survival [6]. Inhibition of CD30 by BV has been proven to be efficacious in lymphoma patients expressing CD30, both in HL and Non-HL.

\section{Case Report}

A 40-year-old Asian female presented with multiple painless lumps on the neck (bilateral), both armpits, and left groin. Ultrasound-guided fine-needle aspiration biopsy was performed on these lumps, and the cytological examination showed nodular sclerosing HL, which was later confirmed by the results of an excisional biopsy (October 14, 2010). Visceral organ and bone involvement were not observed on X-ray and ultrasound examinations, suggesting the diagnosis of stage $3 \mathrm{HL}$. She was scheduled to receive 6 cycles of doxorubicin $\left(25 \mathrm{mg} / \mathrm{m}^{2}\right.$ on days 1 and 15$)$, vinblastine $\left(6 \mathrm{mg} / \mathrm{m}^{2}\right.$ on days 1 and 15$)$, bleomycin (10 old units on days 1 and 15), and dacarbazine (375 mg/m $\mathrm{m}^{2}$ on days 1 and 15) (1st line), but she refused to continue treatment after 4 cycles due to personal reasons. Ultrasound and CT scan were performed 1 month after the 4 th cycle of chemotherapy. Previously noted lymphadenopathies were no longer observed, and the patient was considered to have complete remission (CR).

The patient remained asymptomatic for 3.5 years. In March 2014, she experienced a recurrence of the lumps on her neck, armpits, and groins. Ultrasound and CT scan examination showed multiple cervical, axillary, and inguinal lymphadenopathies, with hypertrophy of her right psoas major muscle, suggesting the presence of muscle infiltration (Fig 1). She also complained of swollen feet, which according to Doppler examination were caused by bilateral thrombosis of the femoral and popliteal veins. She was treated with 7 cycles of ifosfamide $\left(1,700 \mathrm{mg} / \mathrm{m}^{2}\right.$ on days 1 and 2$)$, carboplatin (4 AUC on days 1 and 2 ), etoposide (100 $\mathrm{mg} / \mathrm{m}^{2}$ on days 1 and 2 ), and mesna $\left(1,700 \mathrm{mg} / \mathrm{m}^{2}\right.$ ) (2nd line) followed by involved site radiation therapy. Prophylactic G-CSF was given on days 3-7 of each chemotherapy cycle. She received rivaroxaban (15 mg q.d.) for her deep vein thrombosis. Ultrasound was performed 1 month after the completion of radiotherapy (in January 2015). Her cervical lymphadenopathies were observed to be smaller with some tumor residue left, while lymphadenopathies of the other regions were no longer observed. The patient felt well and refused to receive further treatment.

At the 9-month post-radiotherapy follow-up, she again experienced a recurrence of the lump on her neck, which was bigger than before. She was treated with 4 cycles of gemcitabine $\left(600 \mathrm{mg} / \mathrm{m}^{2}\right)$, vinorelbine $\left(20 \mathrm{mg} / \mathrm{m}^{2}\right)$, ifosfamide $\left(1,700 \mathrm{mg} / \mathrm{m}^{2}\right.$ on days 1 and 2$)$, and mesna $\left(1,700 \mathrm{mg} / \mathrm{m}^{2}\right)$ (3rd line) (October 2015 - January 2016). The patient demonstrated clinical improvements and again refused to continue chemotherapy. Six months after her 3rd line therapy (in December 2016), the patient started to complain of tension headache. A head MRI was performed and no abnormalities were observed. One year after her 3rd line therapy (in August 2017), the patient complained of recurrent headache with progressive neck swelling (Fig 2). fine-needle aspiration biopsy was performed on her right retro-auricular lymph node (August 2017), showing cancerous cells consistent with HL. She was treated with gemcitabine $\left(600 \mathrm{mg} / \mathrm{m}^{2}\right)$, ifosfamide $\left(1,700 \mathrm{mg} / \mathrm{m}^{2}\right.$ on days 1 and 2$)$, mesna $\left(1,700 \mathrm{mg} / \mathrm{m}^{2}\right)$, and prednisone (12-8-0 on days 1-4). The treatment was discontinued after 2 cycles according to the patient's request.

Six months after her 4th line therapy (in February 2018), her headache worsened, and she agreed to receive further treatment. At this point, we had run out of conventional therapeutic options and considered BV in light of its promising results. The patient's CD30 status was unknown, since at the time of her diagnosis (in 2010) BV had not yet been approved, thus 
Fig. 1. CT scan of the abdomen performed after the first episode of relapse in April 2014 (left) versus follow-up CT scan performed in October 2018, 1 month after the completion of 8 cycles of brentuximab vedotin with 3 cycles of gemcitabine (right). Axial (A, B) and coronal (C, D) views showing an enlarged right psoas major muscle (red arrow). The previously enlarged right psoas major muscle (diameter of $7.2 \mathrm{~cm}$ ) has returned to normal size (diameter of $3 \mathrm{~cm}$ ). The previously enlarged left inguinal lymph nodes with a mean diameter of $1.4 \mathrm{~cm}$ (E, red and blue arrows) were no longer observed on follow-up CT $\operatorname{scan}(\mathbf{F})$.

Purwanto et al.: CR of Relapsed Hodgkin's Lymphoma following BV and Gemcitabine Combination Therapy

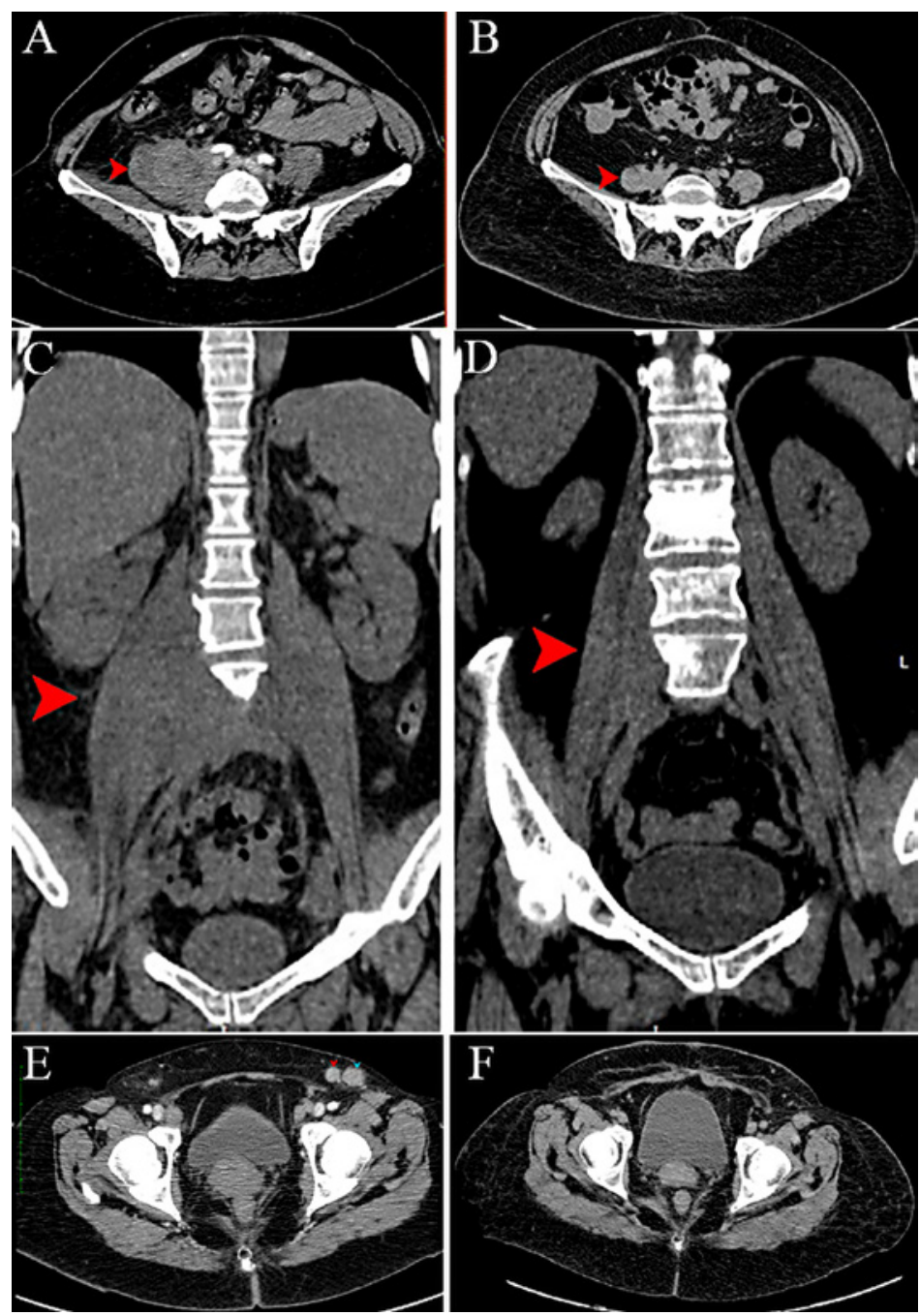

CD30 expression had not been routinely checked, and we were not able to retrieve her biopsy specimen in 2018. With the patient's consent, we prescribed BV $(1.2 \mathrm{mg} / \mathrm{kg})$ for 6 cycles. The patient showed significant clinical improvements after 5 cycles of BV (Fig 1). Gemcitabine $\left(600 \mathrm{mg} / \mathrm{m}^{2}\right.$ on days 1 and 8$)$ was added on the 6th cycle of $\mathrm{BV}$ as an effort to maximize treatment outcome.

PET scan was performed 1 month after the 6th cycle of BV (Fig 3). Compared to previous CT scans, her cervical lymphadenopathy showed PR with tumor residue $<1 \mathrm{~cm}$. She received 2 more cycles of BV $(1.2 \mathrm{mg} / \mathrm{kg})$ with gemcitabine $\left(600 \mathrm{mg} / \mathrm{m}^{2}\right.$ on days 1 and 8) and dexamethasone (40 mg on days 1-4). Another CT scan was performed 1 month after treatment completion. The previously noted lymphadenopathies were no longer observed, and both her liver and spleen appeared to be normal, suggesting a CR. No sign of recurrence was observed on a PET scan performed at the 6-month and the subsequent 18-month post-treatment follow-ups.

A serious adverse event was observed after the addition of gemcitabine on the 6th cycle of BV. The patient developed severe hypotension (50/36 mm Hg) with upper and lower limb petechiae and edema. These symptoms resolved after 3 days' treatment with vasopressor and high-dose corticosteroid. Dexamethasone (40 mg q.d. on days 1-4) was added for the subsequent 2 cycles of $\mathrm{BV}$ and gemcitabine to prevent the recurrence of this adverse event. 


\section{Case Reports in Oncology}

\begin{tabular}{l|l}
\hline Case Rep Oncol 2020;13:341-346 \\
\hline DOI: 10.1159/000505830 & $\begin{array}{l}\text { @ 2020 The Author(s). Published by S. Karger AG, Basel } \\
\text { www.karger.com/cro }\end{array}$ \\
\hline
\end{tabular}

Purwanto et al.: CR of Relapsed Hodgkin's Lymphoma following BV and Gemcitabine Combination Therapy

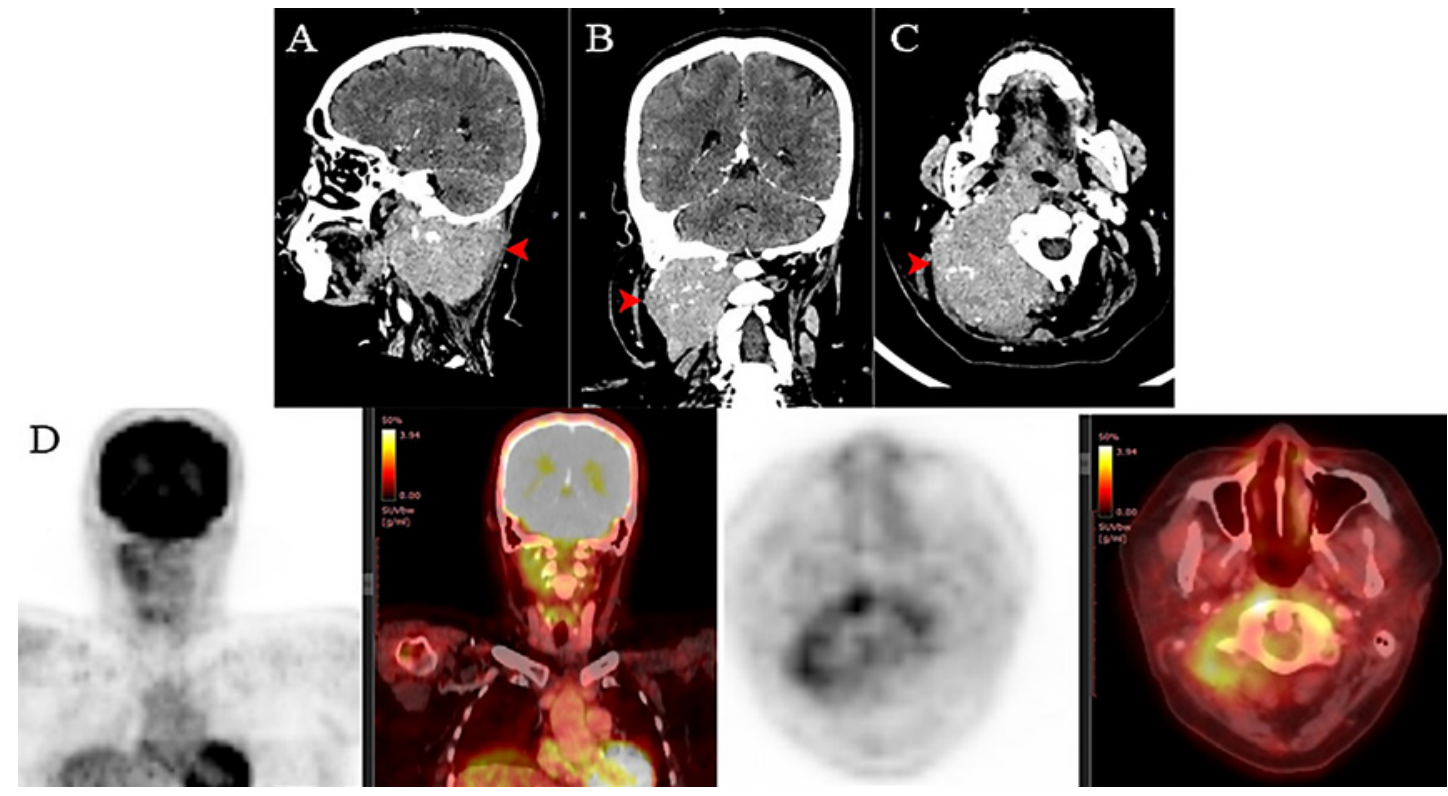

Fig. 2. Cervical CT scan performed before the initiation of brentuximab vedotin (BV) in August 2017 (top), sagittal (A), axial (B), and coronal (C) views showing an enlarged right cervical lymph node (red arrow) on the level of C1-C4 with a diameter of $6.5 \mathrm{~cm}$. D Follow-up PET scan performed after 5 cycles of BV and 1 cycle of BV + gemcitabine in June 2018, showing small residual lesions with mild metabolic activity and a necrotic area, suggesting partial response (PR).



Fig. 3. Whole body CT scan performed 1 month after treatment completion showing no sign of residual lesion. 
Purwanto et al.: CR of Relapsed Hodgkin's Lymphoma following BV and Gemcitabine Combination Therapy

\section{Discussion}

In Indonesia, treatment of relapsed or refractory HL usually revolves around multiple rounds of cytotoxic chemotherapy with or without radiotherapy, since autologous stem-cell transplantation is very limited in Indonesia and does not cover the majority of its population of 264 million people. BV presented as an ideal treatment option in this setting. In 2012, a pivotal phase 2 study by Younes et al. [7] reported that BV monotherapy in relapsed or refractory HL resulted in $75 \%$ objective response rate, with $34 \%$ patients experiencing CR. In our patient, $\mathrm{BV}$ was suitable as multiple rounds of cytotoxic chemotherapy failed to achieve a satisfactory response, and the patient could not tolerate the side effects of these medications, resulting in repeated premature termination of treatment. Furthermore, BV has been observed to show benefit even in lymphoma patients not expressing CD30 [8]. After 5 cycles of BV monotherapy, the patient demonstrated remarkable clinical improvement which was the best outcome since her initial relapse. A lower dose of BV $(1.2 \mathrm{mg} / \mathrm{kg})$ was given in this patient as a precaution for her decreased kidney function (eGFR before BV: $70 \mathrm{~mL} / \mathrm{min} / 1.73$ $\mathrm{m}^{2}$ ). Gemcitabine was added from the 6th until the 8th cycle of BV, as this combination has been reported by the AHOD1221 trial to result in positive outcome in pediatric and young adult patients with relapsed or refractory HL [9]. In this trial, $57 \%$ of all pediatric and young adult patients with relapsed or refractory HL achieved CR within the first 4 cycles of treatment, and 31\% patients experienced PR or stable disease after 4 cycles (AHOD1221 trial) [9].

Three days after the administration of the 1st cycle of BV + gemcitabine, the patient developed severe hypotension $(50 / 36 \mathrm{~mm} \mathrm{Hg})$ with upper and lower limb petechiae and edema, which resolved after 3 days' treatment with vasopressor and high-dose corticosteroid. The Naranjo Adverse Drug Reaction Probability Scale showed that this adverse event was probably treatment related. The addition of dexamethasone (40 mg q.d. on days 1-4) for the subsequent 2 cycles successfully prevented this adverse event from recurring, which allowed the patient to safely complete the treatment regimen.

\section{Conclusion}

Combination of gemcitabine with BV presents as a viable therapeutic option for heavily treated, relapsed HL patient with manageable adverse events.

\section{Acknowledgement}

The authors express their gratitude to Dr. Sardjito General Hospital for providing the necessary data for this publication.

\section{Statement of Ethics}

Written informed consent was obtained from the patient for the publication of this case report and the accompanying images.

\section{Disclosure Statement}

The authors have no conflicts of interest to declare. 
Purwanto et al:: CR of Relapsed Hodgkin's Lymphoma following BV and Gemcitabine Combination Therapy

\section{Funding Sources}

The authors received no financial support for the authorship and/or publication of this case report.

\section{Author Contributions}

All authors have been involved in the work conception, data acquisition, and manuscript drafting.

\section{References}

1 Moccia AA, Donaldson J, Chhanabhai M, Hoskins PJ, Klasa RJ, Savage KJ, et al. International Prognostic Score in advanced-stage Hodgkin's lymphoma: altered utility in the modern era. J Clin Oncol. 2012 Sep;30(27): 3383-8.

2 DeVita VT Jr, Lawrence TS, Rosenberg SA. DeVita, Hellman, and Rosenberg's cancer: principles \& practice of oncology. 8th ed. Philadelphia: Lippincott William \& Wilkins; 2008.

3 Hu S, Xu-Monette ZY, Balasubramanyam A, Manyam GC, Visco C, Tzankov A, et al. CD30 expression defines a novel subgroup of diffuse large B-cell lymphoma with favorable prognosis and distinct gene expression signature: a report from the International DLBCL Rituximab-CHOP Consortium Program Study. Blood. 2013 Apr;121(14):2715-24.

4 Slack GW, Steidl C, Sehn LH, Gascoyne RD. CD30 expression in de novo diffuse large B-cell lymphoma: a population-based study from British Columbia. Br J Haematol. 2014 Dec;167(5):608-17.

5 Onaindia A, Martínez N, Montes-Moreno S, Almaraz C, Rodríguez-Pinilla SM, Cereceda L, et al. CD30 expression by $B$ and T cells: a frequent finding in angioimmunoblastic T-cell lymphoma and peripheral T-cell lymphomanot otherwise specified. Am J Surg Pathol. 2016 Mar;40(3):378-85.

6 van der Weyden CA, Pileri SA, Feldman AL, Whisstock J, Prince HM. Understanding CD30 biology and therapeutic targeting: a historical perspective providing insight into future directions. Blood Cancer J. 2017 Sep; 7(9):e603.

7 Younes A, Gopal AK, Smith SE, Ansell SM, Rosenblatt JD, Savage KJ, et al. Results of a pivotal phase II study of brentuximab vedotin for patients with relapsed or refractory Hodgkin's lymphoma. J Clin Oncol. 2012 Jun; 30(18):2183-9.

8 Goyal A, Hordinsky M, Lazaryan A. Impressive response of CD30-negative, treatment-refractory mycosis fungoides to brentuximab vedotin. Dermatol Ther. 2019 Mar;32(2):e12835.

9 Cole PD, McCarten KM, Pei Q, Spira M, Metzger ML, Drachtman RA, et al. Brentuximab vedotin with gemcitabine for paediatric and young adult patients with relapsed or refractory Hodgkin's lymphoma (AHOD1221): a Children's Oncology Group, multicentre single-arm, phase 1-2 trial. Lancet Oncol. 2018 Sep;19(9):1229-38. 